Article

\title{
Improving Adventitious Shoot Regeneration and Transient Agrobacterium-Mediated Transformation of Apricot (Prunus armeniaca L.) Hypocotyl Sections
}

\author{
Cristian Pérez-Caselles (D), Lydia Faize (D), Lorenzo Burgos (D) and Nuria Alburquerque *(D) \\ Grupo de Biotecnología de Frutales, Departamento de Mejora Vegetal, CEBAS-CSIC, Campus Universitario de \\ Espinardo, 30100 Murcia, Spain; cperez@cebas.csic.es (C.P.-C.); lbremaud@cebas.csic.es (L.F.); \\ burgos@cebas.csic.es (L.B.) \\ * Correspondence: nalbur@cebas.csic.es
}

check for

updates

Citation: Pérez-Caselles, C.; Faize, L.; Burgos, L.; Alburquerque, N. Improving Adventitious Shoot Regeneration and Transient Agrobacterium-Mediated Transformation of Apricot (Prunus armeniaca L.) Hypocotyl Sections. Agronomy 2021, 11, 1338. https:// doi.org/10.3390/agronomy11071338

Academic Editor: Yong-Bao Pan

Received: 21 May 2021

Accepted: 29 June 2021

Published: 30 June 2021

Publisher's Note: MDPI stays neutral with regard to jurisdictional claims in published maps and institutional affiliations.

Copyright: (c) 2021 by the authors. Licensee MDPI, Basel, Switzerland. This article is an open access article distributed under the terms and conditions of the Creative Commons Attribution (CC BY) license (https:/ / creativecommons.org/licenses/by/ $4.0 /)$.

\begin{abstract}
The improvement of previously described protocols for the regeneration of shoots from 'Canino' mature seed hypocotyl slices has been accomplished. The effects of different factors such as the part of the hypocotyl used, vacuum-infiltration, 2,4-Dichlorophenoxyacetic acid pulse, vacuuminfiltration and sonication on regeneration and transient transformation were analyzed. When the three slices obtained from the hypocotyls were evaluated separately on regeneration medium, the highest percentages of regenerating explants were achieved in the part close to the epicotyl and in the central part. On the other hand, sonication of the explants for $30 \mathrm{~s}$ followed by vacuuminfiltration during Agrobacterium infection for $20 \mathrm{~min}$ allowed for an increase in the transformation events. The application of these modifications to the procedure increased the regeneration efficiencies, and transient transformation events and may reduce the frequency of failed experiments. An efficient regeneration/transformation protocol could facilitate its use as a biotechnological technique for apricot breeding.
\end{abstract}

Keywords: organogenesis; genetic transformation; vacuum-infiltration; sonication; auxin pulses

\section{Introduction}

Apricot (Prunus armeniaca L.) breeding programs are focused on obtaining new cultivars resistant to pest and diseases with good quality and adapted to climate change. Biotechnological techniques could be applied to apricot breeding in order to analyze gene functions or to introduce new agronomical traits that cannot be introduced by hybridization and selection. Rhizobium radiobacter (synonymous Agrobacterium tumefaciens) infection is the method used for the production of transgenic apricot plants [1].

The first step for the development of a genetic transformation procedure is the establishment of an efficient regeneration protocol. Other authors have reported the regeneration of transformed apricot plants from cotyledons of immature seeds with the Plum pox virus coat protein [2]. Previously, our group has reported adventitious shoot regeneration from hypocotyl sections of mature apricot seeds of 'Dorada', 'Moniquí', and 'Canino' cultivars with efficiencies that varied from 31 to $47 \%$, depending on the cultivar [3]. After using this protocol, coupled with an antibiotic selection strategy, the regeneration of transformed apricot plants from cv. 'Canino' seeds was described [4]. Additionally, the regeneration of transgenic plants from hypocotyl segments of cv. 'Moniquí' using an herbicide selection strategy was achieved for the first time [4]. However, the transformation efficiencies obtained were low (1.5\% and 3.8\% with antibiotic and phosphinothricin selection, respectively) because apricot is a recalcitrant species for regeneration/transformation procedures.

The optimization of the regeneration procedure could help to improve the efficiency of the transformation protocol. The ability of different explants to regenerate has been widely studied and the explant choice is critical for the success of the adventitious shoot 
regeneration [5]. The effect on regeneration of explant segment position was studied for the establishment of efficient Agrobacterium-mediated protocols using apple leaves (Malus domestica Borkh) [6]. Previous experiments with apricot hypocotyl slices have shown a large variability in regeneration between explants $[3,4]$ and it seemed appropriate to check whether the position of the slice in the hypocotyl influenced the regeneration obtained.

Treatments with 2,4-D during short periods of time have been reported to stimulate regeneration/transformation in different explants of tree species such as apricot leaves [7] or European plum mature hypocotyl slices [8].

The use of vacuum-infiltration in transformation protocols has been described as an important factor to enhance Agrobacterium infection in several plant species. Different authors have reported the successful production of transgenic plants by using this methodology in herbaceous plants like wheat [9] and cotton [10]. There are also some studies confirming that vacuum-infiltration treatments enhanced transformation efficiencies in woody plants such as coffee [11], Pinus radiata [12], and citrus species [13].

Sonication-assisted Agrobacterium-mediated transformation (SAAT) is a methodology that produces wounds in tissues to allow the Agrobacterium access to plant cells. SAAT alone or combined with vacuum infiltration has allowed enhancing the transformation efficiency in many plant species, especially those that are recalcitrant to Agrobacterium-mediated transformation $[14,15]$.

In this work, we analyzed the effect of the part of the explant used on regeneration percentages from apricot mature hypocotyls. Additionally, the effect of 2,4-D pretreatment, sonication, vacuum infiltration, and the combination of the sonication and vacuum treatments on regeneration and transient transformation percentages were studied.

\section{Materials and Methods}

\subsection{Plant Material}

Mature seed hypocotyl slices from the apricot cultivar 'Canino' were used as explants. Seed disinfection and explant preparation were performed following previously published procedures [3]. Briefly, after the endocarp had been removed with a nutcracker, the seeds were disinfected $20 \mathrm{~min}$ with a $1 \%$ sodium hypochlorite solution containing approximately $20 \mu \mathrm{L}$ Tween-20 per $100 \mathrm{~mL}$ solution and then rinsed four times with sterile distilled water in a laminar flow hood. Disinfected seeds were soaked in sterile water overnight at $4{ }^{\circ} \mathrm{C}$. The explants were prepared removing the seed coats with a scalpel, discarding the radicle and the epicotyl, and slicing the hypocotyl into three cross sections $(0.5-1 \mathrm{~mm})$.

\subsection{Study of Factors Affecting Adventitious Shoot Regeneration}

Hypocotyl slices were placed on shoot regeneration medium (SRM) that consisted of 3/4-strength (MS) salts [16] supplemented with full strength MS vitamins (Duchefa Biochemie, Haarlem, The Netherlands), $2 \%(w / v)$ sucrose, $0.7 \%(w / v)$ purified agar (Laboratorios Conda, Madrid, Spain. Cat. No. 1806), $7.0 \mu \mathrm{M}$ thidiazuron (TDZ) and $0.25 \mu \mathrm{M}$ 3 -indolebutyric acid (IBA). The medium was adjusted with $1 \mathrm{~N} \mathrm{NaOH}$ solution to $\mathrm{pH} 5.8$, autoclaved at $121{ }^{\circ} \mathrm{C}$ for $20 \mathrm{~min}$, and then dispensed into $9 \mathrm{~cm} \times 1.5 \mathrm{~cm}$ sterile plastic Petri dishes ( 25 mL each). Explants were positioned on the SRM and incubated at $23 \pm 1{ }^{\circ} \mathrm{C}$ with a $16 \mathrm{~h}$ photoperiod (20-25 $\mu \mathrm{mol} \mathrm{m} \mathrm{m}^{-2} \mathrm{~s}^{-1}$, white fluorescent lamps) for six weeks.

To study the effect of explant section on regeneration, three slices from 'Canino' hypocotyls were placed for six weeks on SRM separately: the slice closed to the radicle (r), the central pa€ (c), and the slice closed to the epicotyl (a) (Figure 1A).

In another experiment 'Canino' hypocotyl sections were placed on SRM supplemented or not with $9 \mu \mathrm{M}$ of 2,4-D for three days and cultured in the dark at $23 \pm 1{ }^{\circ} \mathrm{C}$. After three days, explants were transferred to SRM without 2,4-D and cultured under a $16 \mathrm{~h}$ photoperiod $\left(20-25 \mu \mathrm{mol} \mathrm{m}{ }^{-2} \mathrm{~s}^{-1}\right)$ at $23 \pm 1{ }^{\circ} \mathrm{C}$ for six weeks. 

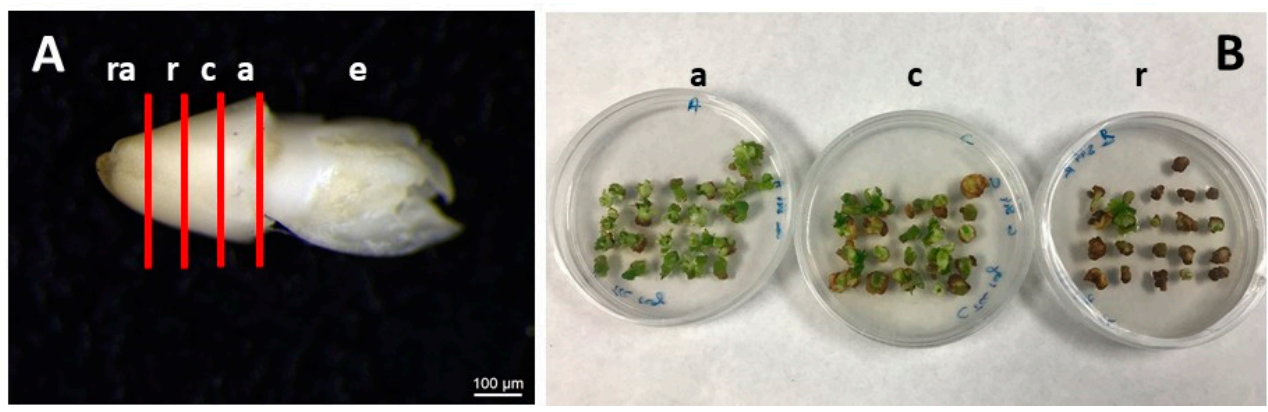

Figure 1. Shoot regeneration from 'Canino' apricot mature seeds hypocotyl slices (A) Different apricot hypocotyl slices used in this study: the slice near the epicotyl (a), the central slice (c), the slice near the ra€le (r). €cotyl (e) and radicle (ra) were not used. (B) Regeneration pattern from different hypocotyl slices (a, $\mathrm{c}$ and $\mathrm{r}$ ).

The effect of vacuum on adventitious regeneration was also studied. The vacuum system consisted of a vacuum pump $(-600 \mathrm{~mm} \mathrm{Hg})$ attached to a desiccator. 'Canino' hypocotyl slices were immersed in liquid SRM (SRLM) in plates that were placed in the desiccator and vacuum was applied for $20 \mathrm{~min}$. After the treatment, explants were placed on SRM with 0 or $9 \mu \mathrm{M}$ of 2,4-D and cultured as described above.

Sonication treatments consisted of application of ultrasound (SELECTA sonicator $3000514,40 \mathrm{KHz}, 200 \mathrm{~W}$, J.P. Selecta, Barcelona, Spain) during 0 (control), 10, 20, or $30 \mathrm{~s}$ alone or combined with 20 min vacuum-infiltration after sonication. The explants were then placed on SRM without 2,4-D to observe regeneration percentages.

Regeneration percentages were recorded six weeks after the beginning of the experiments.

\subsection{Agrobacterium Tumefaciens-Mediated Transformation}

Agrobacterium tumefaciens strain LB4404 carrying the binary plasmid pMOG-eyfp-IV2 was used in this study. The plasmid contains the nptII gene for plant selection and the reporter gene eyfp, which contained an intron (IV2) derived from the potato (Solanum tuberosum) ST-LS1 gene [17] to ensure plant-specific expression.

A single colony of the LB4404-pMOG-eyfp-IV2 strain was inoculated into $10 \mathrm{~mL}$ of Luria-Bertani medium with $34.3 \mu \mathrm{M}$ streptomycin sulfate and $83.3 \mu \mathrm{M}$ kanamycin sulfate, and incubated overnight at $28^{\circ} \mathrm{C}$ with constant agitation (150 rpm), reaching an OD600 of $0.4-1.0$. The cultures were centrifuged at $3000 \times g$ for $15 \mathrm{~min}$ and suspended in $50 \mathrm{~mL}$ of bacterial infection medium (MS salts, $2 \%(w / v)$ sucrose, and $100 \mu \mathrm{M}$ acetosyringone). The culture in the bacterial infection medium was shaken $(175 \mathrm{rpm})$ at $25^{\circ} \mathrm{C}$ for $5 \mathrm{~h}$ before use.

Hypocotyl slices were immersed in the Agrobacterium suspension for 20 min with or without vacuum-infiltration (control). Sonication treatments consisted of application of ultrasounds to the explants immersed in liquid SRM for 10 or $30 \mathrm{~s}$ followed by infection of explants with Agrobacterium solution applying vacuum infiltration (20 min). Afterward, Agrobacterium-infection hypocotyls slices were blotted briefly on sterile filter paper. Control and vacuum-infiltrated explant were co-cultivated on SRM with 0 or $9 \mu \mathrm{M}$ of 2,4-D and without antibiotics. Sonicated explants were co-cultivated on SRM without 2,4-D. After three days, explants were washed in a sterile solution of 1/2-strength MS medium with $300 \mathrm{mg} \mathrm{L}^{-1}$ cefotaxime, blotted briefly on sterile filter paper and then placed on SRM with $300 \mathrm{mg} \mathrm{L}^{-1}$ cefotaxime and $10 \mu \mathrm{M}$ paromomycin.

Explants were examined under a Leica MZ10F fluorescence stereomicroscope (Wetzlar, Germany) to detect GFP (Green Fluorescent Protein) expression four weeks after the infection in order to determine transient transformation. The number of zones expressing GFP per transformed explant was recorded. In addition, the percentage of the explant expressing GFP was observed. 


\subsection{Experimental Design and Data Analysis}

An average of 30 explants per treatment was evaluated for each experiment. Experiments were repeated, at least, three times.

Regeneration efficiencies were calculated as the number of explants that regenerated per total number of explants and the percentages of chimerical buds were calculated as the number of regenerated buds expressing some GFP per total number of Agrobacteriuminfected explants.

Regeneration and percentage of chimerical buds were analyzed by using maximum likelihood ANOVA from the CATMOD module in SAS [18] and specific contrasts were designed when necessary. Number of GFP zones per transformed explant and the portion of the explant expressing GFP were analyzed with one-way ANOVA, and means were compared to the control using a Dunnett's test.

\section{Results}

\subsection{Adventitious Regeneration}

When the three sections obtained from the hypocotyls were separated and placed on SRM, different regeneration responses $(p<0.001)$ were observed (Figure 1B). The hypocotyl section closer to the radicle $(r)$ showed the lowest regeneration potential $(2.4 \pm 2.4)$. The highest percentage $(78.1 \pm 6.5)$ was observed in the section closer to the epicotyl (a), followed by the central section (c) with $29.3 \pm 7.1 \%$. In order to increase the proportion of explants with regenerating buds, the $\mathrm{r}$ section was discarded in the next experiments, and only two sections (a and c) per seed were processed.

Treatments with 2,4-D, vacuum-infiltration and the combination of both treatments did not produce significant differences on the regeneration from 'Canino' non-infected hypocotyl sections (Figure 2). When explants were infected with Agrobacterium, significant differences in regeneration percentages among 2,4-D and vacuum-infiltration treatments were observed $(p<0.05)$. The best treatment applied was vacuum-infiltration (Figure 2$)$.

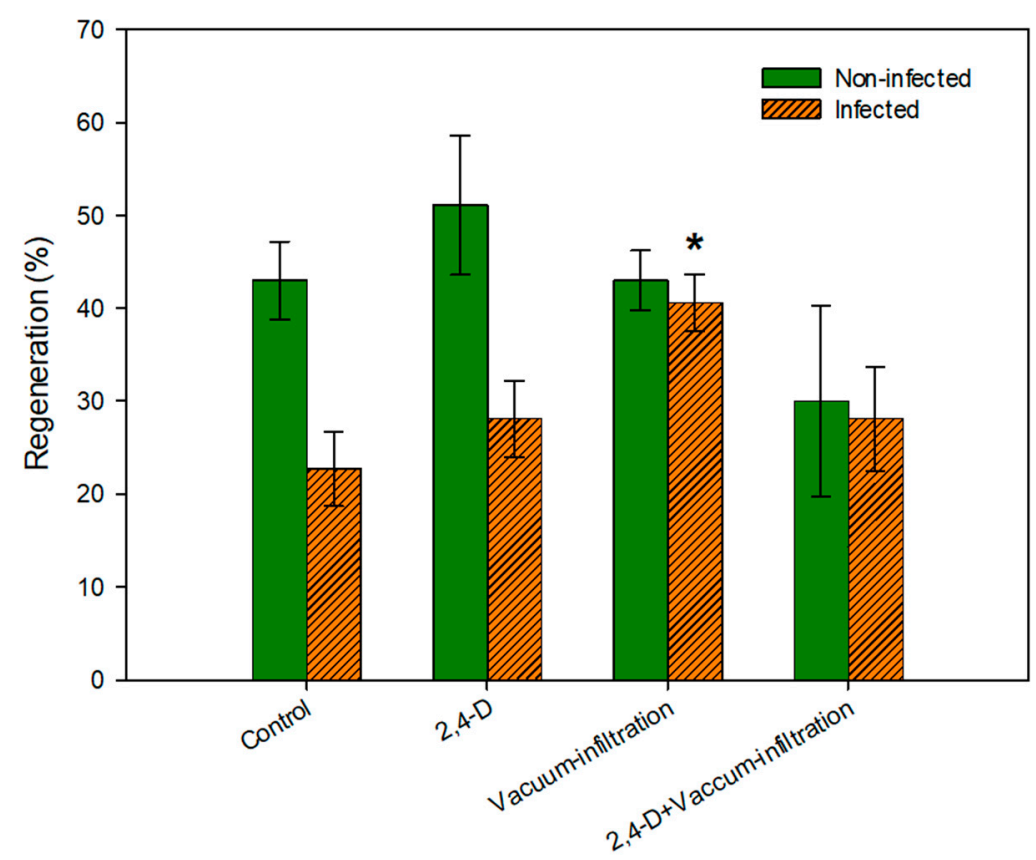

Figure 2. Effect of 2,4-D, 20 min of vacuum-infiltration and the combination of both treatments on adventitious shoot regeneration from hypocotyl slices of non-infected 'Canino' mature seeds (green) and infected with Agrobacterium harboring the plasmid pMOG-eyfp-IV2 (orange with striped pattern). Data were collected six weeks after the beginning of the experiments. Asterisks denote significant differences in regeneration percentages with the control according to specific contrasts $(p<0.05)$ within non-infected or infected explants. 
Sonication for 10, 20, or $30 \mathrm{~s}$ alone or combined with 20 min of vacuum-infiltration did not affect the regeneration ability of non-infected explants (Figure 3). Although no significant differences were observed among the sonication treatments and control (0 s), when $30 \mathrm{~s}$ of sonication was applied, the regeneration percentages were slightly higher than under the control conditions, reaching the highest value (54.8\%, Figure 3$)$.

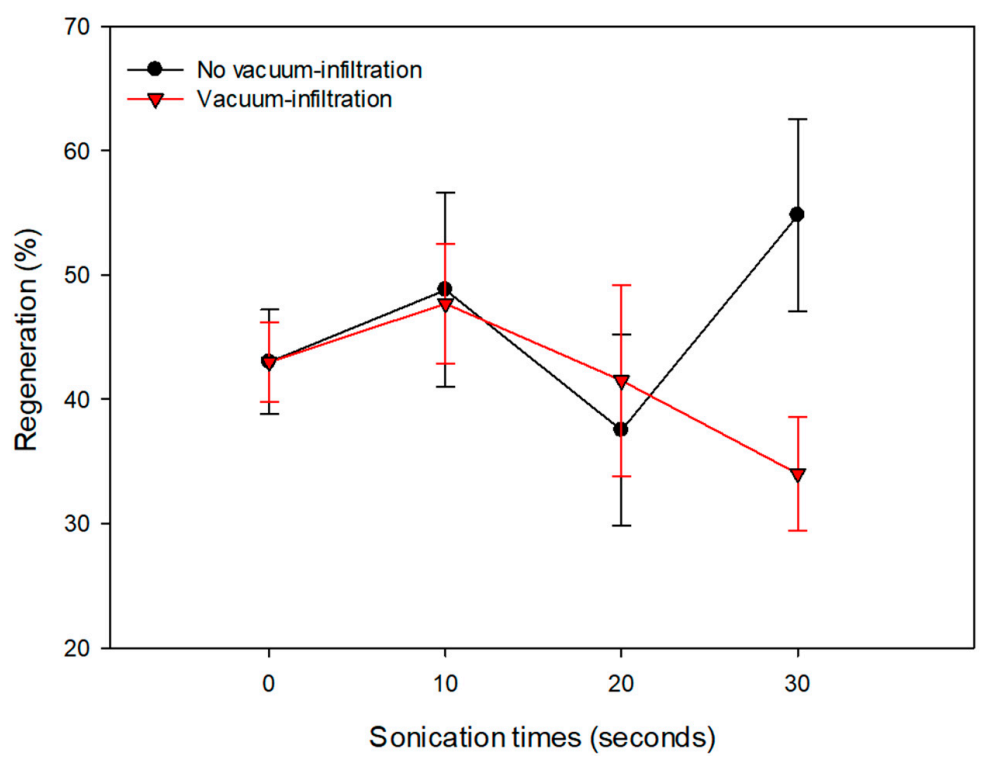

Figure 3. Effect of sonication treatments alone and combined with $20 \mathrm{~min}$ of vacuum-infiltration on adventitious shoot regeneration from hypocotyls slices of non-infected 'Canino' mature seeds. Data were collected six weeks after the beginning of the experiments.

However, when explants were infected with Agrobacterium, the application of $20 \mathrm{~min}$ vacuum-infiltration alone or combined with sonication during 10 or $30 \mathrm{~s}$ significantly increased the number of regenerated explants compared with the control conditions $(p<0.05)$, reaching regeneration percentages of $40 \%$ approximately (Figure 4 ).

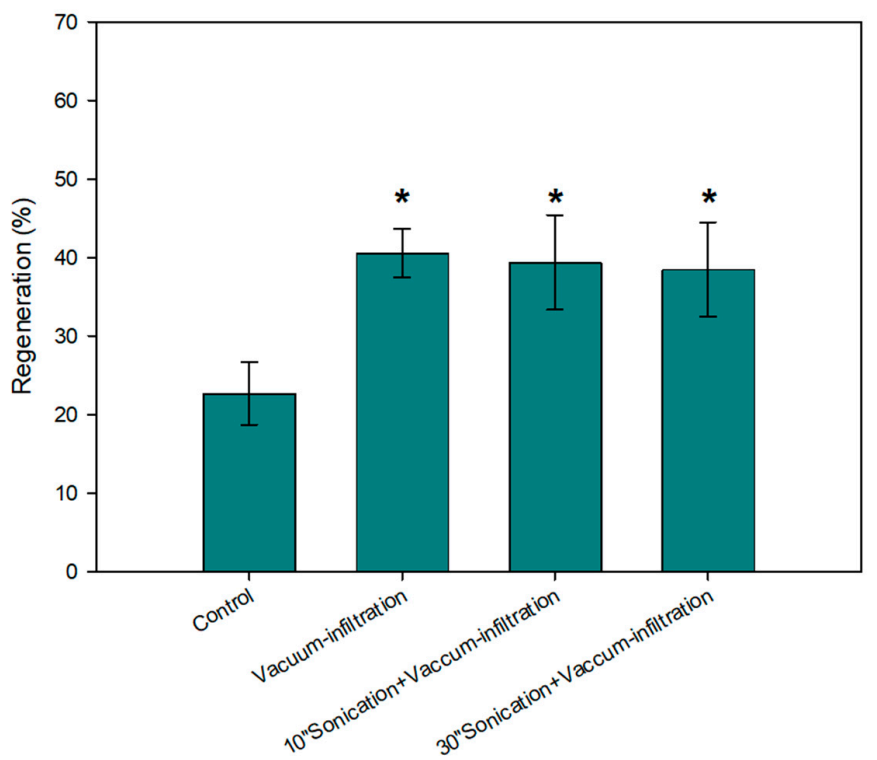

Figure 4. Effect of sonication treatments combined with $20 \mathrm{~min}$ of vacuum-infiltration on adventitious shoot regeneration from hypocotyl slices of non-infected 'Canino' mature seeds and infected with Agrobacterium harboring the plasmid pMOG-eyfp-IV2. Data were collected six weeks after the beginning of the experiments. Asterisks denote significant differences in regeneration percentages with the control according to specific contrasts $(p<0.05)$ within infected explants. 


\subsection{Tissue Transformation}

Transformation events were observed four weeks after infection as spots or large zones expressing GFP (Figure 5A). Transformation percentages, based on the number of explants expressing GFP, were not affected by the treatments applied, achieving $100 \%$ in all cases. However, the number of zones expressing GFP was significantly influenced $(p<0.01)$ by the treatments applied (Table 1). Values were higher when a 2,4-D pulse was added after Agrobacterium infection or $30 \mathrm{~s}$ sonication plus vacuum-infiltration, during infection, were applied. Nevertheless, the zones expressing GFP, in explants treated with 2,4-D, were mainly calli, where no regeneration was observed.
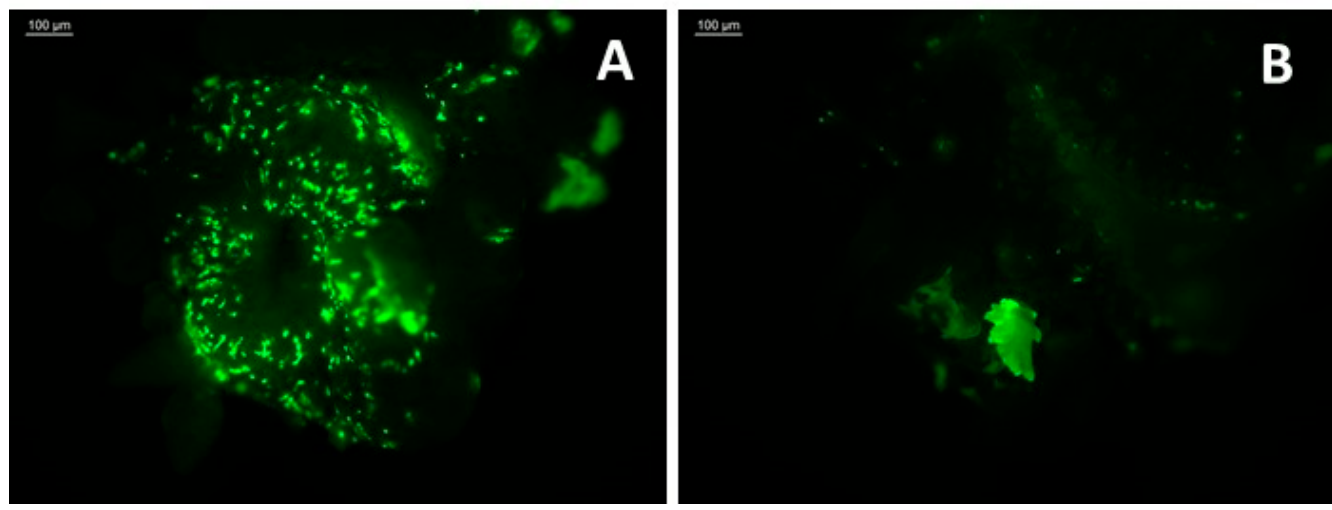

Figure 5. GFP expression of 'Canino' hypocotyl slices four weeks after infection with the Agrobacterium tumefaciens strain LB4404 harboring the pMOG-eyfp-IV2 plasmid. (A) Transformation events as spots and zones expressing GFP. (B) Chimerical bud showing GFP-expressing zones in some leaves.

Table 1. Transformation of 'Canino' hypocotyl slices by LBA4401 carrying pMOG-eyfp-IV2 based on GFP expression.

\begin{tabular}{cccc}
\hline Treatment & $\begin{array}{c}\text { Number of GFP } \\
\text { Zones/Transformed Explant }\end{array}$ & $\begin{array}{c}\text { Explant Area } \\
\text { Expressing GFP\% }\end{array}$ & $\begin{array}{c}\text { Chimerical Buds/Total } \\
\text { Infected Explants\% }\end{array}$ \\
\hline Control & $0.9 \pm 0.1$ & $29.1 \pm 0.9$ & $1.8 \pm 1.3$ \\
\hline 2,4-D & $2.0 \pm 0.2 *$ & $30.8 \pm 1.0$ & $0.0 \pm 0.0$ \\
\hline Vacuum-infiltration & $1.1 \pm 0.1$ & $34.8 \pm 1.1 *$ & $10.8 \pm 2.3 *$ \\
\hline 2,4-D + Vacuum-infiltration & $1.1 \pm 0.2$ & $33.9 \pm 1.7 *$ & $1.6 \pm 1.5$ \\
\hline 10" Sonication + Vacuum-infiltration & $0.3 \pm 0.1$ & $27.3 \pm 1.0$ & $11.4 \pm 3.8^{*}$ \\
\hline 30 Sonication + Vacuum-infiltration & $1.4 \pm 0.2 *$ & $35.6 \pm 1.8^{*}$ & $15.4 \pm 4.5 *$ \\
\hline
\end{tabular}

* Asterisks denote significant differences with the control, according to a Dunnett's test $(p<0.05)$, for the number of GFP zones and the percentage of explant area expressing GFP. For percentage of chimerical buds, asterisks denote significant differences between treatments and the control according to specific contrasts $(p<0.05)$ after data were analyzed using maximum likelihood ANOVA.

The percentage of explants expressing GFP was also influenced by the treatment $(p<0.001)$. Although in all cases the percentage of the explants expressing GFP were over $25 \%$ (Table 1 ), the vacuum-infiltration and the combination of this treatment with 2,4-D pulse or with $30 \mathrm{~s}$ sonication showed the highest percentages, around 35\% (Table 1).

Some chimerical buds could be observed (Figure 5B). Table 1 shows the percentages of chimerical buds with some areas expressing GFP regarding the total number of Agrobacterium-infected explants. The highest values were recorded when vacuum-infiltration alone or combined with $10 \mathrm{~s}$ or $30 \mathrm{~s}$ sonication were applied $(10.8,11.4$ and $15.4 \%$, respectively). However, the percentage decreased to $1.8 \%$ with control conditions and $1.65 \%$ with the combination of auxin pulse and vacuum-infiltration whereas no chimerical buds were observed in the 2,4-D treatment. 


\section{Discussion}

Adventitious regeneration and transformation are recalcitrant processes in some species such as most of the woody perennial fruit trees. There are numerous factors influencing the morphogenesis of new buds from dedifferentiated tissues. Thus, the cultivar providing explants, the medium composition, the growth regulator concentrations, the light conditions, or the addition of the ethylene inhibitor silver thiosulfate (STS) were previously studied and a regeneration protocol from apricot mature seed hypocotyl slices was established [3]. Afterward, using this regeneration procedure, a protocol to produce transgenic apricot plants by Agrobacterium-mediated infection was reported for the first time [4]. In this work, the influence of the different hypocotyl slices used, the possible influences of a 2,4-D pulse at high concentration, the vacuum-infiltration and sonication on both regeneration and transient transformation percentages were analyzed.

Yepes et al. [19] analyzed the effect of the segment position of apple leaves on regeneration capacity and indicated that it increased dramatically from the tip toward the base of the leaf. The capacity of embryogenic callus induction from rice leaves was different among the three portions of leaf segment analyzed, recording just regenerable callus in the segment near the leaf base [20]. Similarly, Haliloglu [21] indicated that the embryogenic and plant regeneration potential of wheat leaf tissue was influenced by the position of the leaf segment, decreasing the efficiency from the leaf base to tip. Callus induction and plant regeneration from roots of in vitro garlic plants were affected by root segment position and it was higher on apical segments (average 88.33\%) than on non-apical segments (average $61.25 \%$ ) [22]. Results in this manuscript suggest that the position of the hypocotyl slice in the mature embryo has a strong influence on regeneration, recording the lowest percentages from the slices near the radicle and the highest values from those close to the caulinar meristem. The best regeneration percentage reached for cv. 'Canino' using three hypocotyl slices was $31.7 \%$ [3]. However, we have demonstrated that the use of the sections with the best regeneration ability allows for an improvement in the average regeneration efficiencies around $50 \%$. Welander [23] suggested that the increased regeneration ability observed from the tip toward the base of the apple leaves could be correlated with differences in growth regulators and nutrient concentrations or the presence of vascular tissue. Mante et al. [24] indicated that new shoots originated from meristematic cells in the sub-epidermal layers of European plum hypocotyl sections. The presence of different amounts of dedifferentiated cells along the apricot hypocotyls could be the reason for the different regeneration ratios obtained from the different apricot hypocotyl sections.

Pulses with 2,4-D have been shown to improve regeneration from leaf explants of adult Prunus rootstocks [25], callus cultures of white pinus (Pinus strobus L.) [26], or apple leaves [27]. We previously described that four-day pulses with 2,4-D significantly increased shoot regeneration and stable transformation events from apricot leaves [7].

The addition of 2,4-D to the co-cultivation medium after Agrobacterium infection improved the transformation percentages of plum hypocotyl slices up to ten-fold, reaching $42 \%$ of explants producing transgenic plants [8]. However, no influence of 2,4-D pulses at $1.12,2.25$ or $4.5 \mu \mathrm{M}$ on regeneration percentages from apricot hypocotyl slices were observed [3]. In the same way, our results indicate that 2,4-D at $9.05 \mu \mathrm{M}$ does not significantly stimulate cell division and adventitious organogenesis or transformation of hypocotyl slices in apricot.

Shoot regeneration was stimulated by brief periods of ultrasounds in recalcitrant squash cotyledon explants [28]. Our results showed that sonication periods of 10, 20, or $30 \mathrm{~s}$ had no effect on adventitious regeneration from apricot hypocotyl sections. However, when regeneration was obtained from Agrobacterium infected explants, we observed a positive effect on regeneration of 10 or $30 \mathrm{~s}$ sonication followed by vacuum-infiltration of the Agrobacterium solution during $20 \mathrm{~min}$. Agrobacterium infection typically induces stress [29]. A plausible explanation of our results may be that the stress caused by Agrobacterium infection coupled with the low selection that is applied in the first steps improve regeneration. 
A positive effect of SAAT on transient and stable transformation has been observed in different species like soybean [14], flax [30] and black locust [31]. Vacuum-infiltration combined with SAAT enhanced transformation efficiencies in soybean [32], Withania somnifera [33] and watermelon cv. Arka manic [34]. However, there are few works reporting the use of SAAT and vacuum-infiltration in woody plants. The effect of both treatments has mainly been measured on transient transformation efficiencies of some woody species. Thus an Agrobacterium-mediated transformation procedure was reported using cotyledons of Pinus radiata zygotic embryos achieving transient transformation efficiencies of $55 \%$ when the explants were vacuum-infiltrated for $5 \mathrm{~min}$ [12]. Recently, vacuum-infiltration has been reported as the most critical factor affecting transient transformation efficiency in persimmon (Diospyros kaki Thunb.) seedlings cultured in vitro and a highly efficient Agrobacterium-mediated transformation system using sonication followed by vacuum infiltration for $20 \mathrm{~min}$ was described [35].

Likewise, Chevreau et al. [36] compared different methods of Agrobacterium tumefaciens inoculation using apple leaves from cv. 'Gala'. They found that transformation efficiencies increased when leaves were vacuum-infiltrated for one min in an Agrobacterium solution compared to the method of crushing the explants before infection by immersion into the inoculum. The authors also reported a dramatic increase in the of transformation efficiency of pear leaves (cv. 'Conference') compared to inoculation with a scalpel dipped into the Agrobacterium inoculum.

A negative effect on regeneration efficiencies obtained from epicotyl explants of 'Pineapple' sweet orange and 'Swingle' citrumelo was observed when vacuum-infiltration treatments were applied [13]. However, these authors reported that incorporating vacuuminfiltration to a conventional Agrobacterium-mediated transformation of 'Pineapple' epicotyl explants increased transformation efficiencies, reaching the highest values with the combination of SAAT during $2 \mathrm{~s}$ followed by $10 \mathrm{~min}$ of vacuum-infiltration.

Our results indicate that vacuum-infiltration is a critical factor for the regeneration of Agrobacterium-infected apricot hypocotyl sections. The application of vacuuminfiltration during $20 \mathrm{~min}$ alone or in combination with sonication during 10 or $30 \mathrm{~s}$ successfully induced regeneration from Agrobacterium-infected apricot hypocotyls. Additionally, more transformation events and regenerated chimerical buds with some area expressing GFP were obtained applying the vacuum-infiltration treatment alone or with previous sonication of apricot 'Canino' hypocotyl slices. It is known that sonication and vacuum-infiltration improves the penetration of Agrobacterium into the plant cells. The sonication process can create wounds [37] and the application of vacuum-infiltration can facilitate the accessibility of the bacteria and the T-DNA transfer to the plant cells [13]. These techniques alone or combined have been incorporated to several plant regeneration/transformation protocols.

The production of chimeras is common in many plant species, especially in the case of woody plants [38]. Chimeras can be dissociated following protocols developed in our laboratory [4]. However, transformation efficiencies of woody species such as apricot are very low and a large number of explants are required to produce uniformly transformed plants. Unfortunately, no uniform transformed apricot lines have been established from the chimerical buds obtained during the experiments developed in this work, although some of the treatments have clearly improved our protocols.

\section{Conclusions}

In this work, we improved the previous described regeneration protocol from 'Canino' mature seed hypocotyl slices. The use of only two slices per seed closer to the caulinar meristem improved the regeneration percentages. In addition, the vacuum-infiltration treatment for 20 min during Agrobacterium infection alone or with previous sonication of the explants for $30 \mathrm{~s}$ allowed for increasing the number of transgenic events observed. The application of these conditions could reduce the frequency of failed experiments and 
increase transformation efficiencies, although further experiments and a larger number of explants are probably needed to produce transgenic apricot shoots.

An efficient regeneration and Agrobacterium-mediated transformation protocol could facilitate its use as a biotechnological technique for apricot breeding, looking for introducing resistance to biotic or abiotic stresses or modifying traits.

Author Contributions: Conceptualization, N.A.; Methodology, C.P.-C. and L.F.; Investigation, C.P.C., L.B. and N.A.; Writing—original draft preparation C.P.-C.; Writing—review \& editing, N.A. and L.B.; Supervision, N.A. and L.B. All authors have read and agreed to the published version of the manuscript.

Funding: This research was supported by the project INIA RTA2017-00011-C03-02 cofinanced by FEDER funds. C.P.-C. has an FPU grant (Formación de Profesorado Universitario) from the Spanish Ministry of Science, Innovation and University.

Institutional Review Board Statement: Not applicable.

Informed Consent Statement: Not applicable.

Data Availability Statement: Data are contained within the article.

Conflicts of Interest: The authors declare no conflict of interest.

\section{References}

1. Alburquerque, N.; Ruiz, D.; Burgos, L.; Petri, C. Prunus Armeniaca Apricot. In Biotechnology of Fruit and Nut Crops; Litz, R.E., Pliego, F., Hormaza, I., Eds.; CAB International: Orlando, FL, USA, 2020; pp. 496-511.

2. Machado, M.L.D.C.; Machado, A.D.C.; Hanzer, V.; Weiss, H.; Regner, F.; Steinkellner, H.; Mattanovich, D.; Plail, R.; Knapp, E.; Kalthoff, B.; et al. Regeneration of transgenic plants of Prunus armeniaca containing the coat protein gene of Plum Pox Virus. Plant Cell Rep. 1992, 11, 25-29. [CrossRef] [PubMed]

3. Wang, H.; Alburquerque, N.; Burgos, L.; Petri, C. Adventitious shoot regeneration from hypocotyl slices of mature apricot (Prunus armeniaca L.) seeds: A feasible alternative for apricot genetic engineering. Sci. Hortic. 2011, 128, 457-464. [CrossRef]

4. Petri, C.; Wang, H.; Burgos, L.; Sánchez-Navarro, J.; Alburquerque, N. Production of transgenic apricot plants from hypocotyl segments of mature seeds. Sci. Hortic. 2015, 197, 144-149. [CrossRef]

5. Piqueras, A.; Alburquerque, N.; Folta, K.M. Explants Used for the Generation of Transgenic Plants. In Transgenic Crop Plants; Springer: Berlin/Heidelberg, Germany, 2010; Volume 1, pp. 31-56.

6. Yepes, L.M.; Aldwinckle, H.S. Factors that affect leaf regeneration efficiency in apple, and effect of antibiotics in morphogenesis. Plant Cell. Tissue Organ Cult. 1994, 37, 257-269.

7. Petri, C.; Alburquerque, N.; Burgos, L. Auxin pulses and a synergistic interaction between polyamines and ethylene inhibitors improve adventitious regeneration from apricot leaves and Agrobacterium-mediated transformation of leaf tissues. Plant Cell. Tissue Organ Cult. (PCTOC) 2005, 82, 105-111. [CrossRef]

8. Petri, C.; Webb, K.; Hily, J.-M.; Dardick, C.; Scorza, R. High transformation efficiency in plum (Prunus domestica L.): A new tool for functional genomics studies in Prunus spp. Mol. Breed. 2008, 22, 581-591. [CrossRef]

9. Amoah, B.; Wu, H.; Sparks, C.; Jones, H. Factors influencing Agrobacterium-mediated transient expression of uidA in wheat inflorescence tissue. J. Exp. Bot. 2001, 52, 1135-1142. [CrossRef]

10. Haq, I.-U. Agrobacterium-mediated transformation of cotton (Gossypium hirsutum L.) via vacuum infiltration. Plant Mol. Biol. Rep. 2004, 22, 279-288. [CrossRef]

11. Canche-Moo, R.; Ku-Gonzalez, A.; Burgeff, C.; Loyola-Vargas, V.; Rodriguez-Zapata, L.; Castano, E. Genetic transformation of Coffea canephora by vacuum infiltration. Plant Cell. Tissue Organ Cult. (PCTOC) 2006, 84, 373-377. [CrossRef]

12. Charity, J.; Holland, L.; Donaldson, S.; Grace, L.; Walter, C. Agrobacterium-mediated transformation of Pinus radiata organogenic tissue using vacuum-infiltration. Plant Cell. Tissue Organ Cult. (PCTOC) 2002, 70, 51-60. [CrossRef]

13. De Oliveira, M.L.P.; Febres, V.J.; Costa, M.G.C.; Moore, G.A.; Otoni, W.C. High-efficiency Agrobacterium-mediated transformation of citrus via sonication and vacuum infiltration. Plant Cell Rep. 2008, 28, 387-395. [CrossRef]

14. Trick, H.; Finer, J. SAAT: Sonication-assisted Agrobacterium-mediated transformation. Transgenic Res. 1997, 6, 329-336. [CrossRef]

15. Liu, Y.; Yang, H.; Sakanishi, A. Ultrasound: Mechanical gene transfer into plant cells by sonoporation. Biotechnol. Adv. 2006, 24, 1-16. [CrossRef] [PubMed]

16. Murashige, T.; Skoog, F. A Revised Medium for Rapid Growth and Bio Assays with Tobacco Tissue Cultures. Physiol. Plant. 1962, 15, 473-497. [CrossRef]

17. Eckes, P.; Rosahl, S.; Schell, J.; Willmitzer, L. Isolation and characterization of a light-inducible, organ-specific gene from potato and analysis of its expression after tagging and transfer into tobacco and potato shoots. Mol. Genet. Genom. 1986, 205, 14-22. [CrossRef]

18. SAS Institute, Inc. SAS/STAT User's Guide. Release 6.03; SAS Institute, Inc.: Cary, NC, USA, 1988. 
19. Yepes, L.M.; Aldwinckle, H.S. Micropropagation of thirteen Malus cultivars and rootstocks, and effect of antibiotics on proliferation. Plant Growth Regul. 1994, 15, 55-67. [CrossRef]

20. Ramesh, M.; Murugiah, V.; Gupta, A. Efficient in vitro plant regeneration via leaf base segments of Indica rice (Oryza sativa L.). Indian J. Exp. Boil. 2009, 47, 68-74.

21. Haliloglu, K. Efficient regeneration system from wheat leaf base segments. Biol. Plant. 2006, 50, 326-330. [CrossRef]

22. Zheng, S.-J.; Henken, B.; Krens, F.A.; Kik, C. The development of an efficient cultivar-independent plant regeneration system from callus derived from both apical and non-apical root segments of garlic (Allium sativum L.). Vitr. Cell. Dev. Biol. Anim. 2003, 39, 288-292. [CrossRef]

23. Welander, M. Plant Regeneration from Leaf and Stem Segments of Shoots Raised in vitro from Mature Apple Trees. J. Plant Physiol. 1988, 132, 738-744. [CrossRef]

24. Manté, S.; Morgens, P.H.; Scorza, R.; Cordts, J.M.; Callahan, A.M. Agrobacterium-Mediated Transformation of Plum (Prunus domestica L.) Hypocotyl Slices and Regeneration of Transgenic Plants. Nat. Biotechnol. 1991, 9, 853-857. [CrossRef]

25. Pascual, L.; Marín, J.A. A liquid 2,4-D pulse increased shoot and root regeneration from leaf explants of adult Prunus rootstocks Sci. Hortic. 2005, 106, 582-592. [CrossRef]

26. Tang, W.; Newton, R.J. Plant regeneration from callus cultures derived from mature zygotic embryos in white pine (Pinus strobus L.). Plant Cell Rep. 2005, 24, 1-9. [CrossRef] [PubMed]

27. Yancheva, S.D.; Golubowicz, S.; Fisher, E.; Lev-Yadun, S.; Flaishman, M.A. Auxin type and timing of application determine the activation of the developmental program during in vitro organogenesis in apple. Plant Sci. 2003, 165, 299-309. [CrossRef]

28. Ananthakrishnan, G.; Xia, X.; Amutha, S.; Singer, S.; Muruganantham, M.; Yablonsky, S.; Fischer, E.; Gaba, V.; Singer, S. Ultrasonic treatment stimulates multiple shoot regeneration and explant enlargement in recalcitrant squash cotyledon explants in vitro. Plant Cell Rep. 2006, 26, 267-276. [CrossRef] [PubMed]

29. Dan, Y.; Zhang, S.; Zhong, H.; Yi, H.; Sainz, M.B. Novel compounds that enhance Agrobacterium-mediated plant transformation by mitigating oxidative stress. Plant Cell Rep. 2014, 34, 291-309. [CrossRef]

30. Beranová, M.; Rakousky, S.; Vávrová, Z.; Skalicky, T. Sonication assisted Agrobacterium-mediated transformation enhances the transformation efficiency in flax (Linum usitatissimum L.). Plant Cell. Tissue Organ Cult. 2008, 94, 253-259. [CrossRef]

31. Arrillaga, I.; Zaragoza, C.; Muñoz-Bertomeu, J. Regeneration of herbicide-tolerant black locust transgenic plants by SAAT. Plant Cell Rep. 2004, 22, 832-838. [CrossRef]

32. Arun, M.; Subramanyam, K.; Mariashibu, T.S.; Theboral, J.; Sivanandhan, G.; Manickavasagam, M.; Ganapathi, A. Application of Sonication in Combination with Vacuum Infiltration Enhances the Agrobacterium-Mediated Genetic Transformation in Indian Soybean Cultivars. Appl. Biochem. Biotechnol. 2014, 175, 2266-2287. [CrossRef]

33. Sivanandhan, G.; Dev, G.K.; Theboral, J.; Selvaraj, N.; Ganapathi, A.; Manickavasagam, M. Sonication, Vacuum Infiltration and Thiol Compounds Enhance the Agrobacterium-Mediated Transformation Frequency of Withania somnifera (L.) Dunal. PLoS ONE 2015, 10, e0124693. [CrossRef]

34. Vasudevan, V.; Siva, R.; Krishnan, V.; Manickavasagam, M. Polyamines, sonication and vacuum infiltration enhances the Agrobacterium-mediated transformation in watermelon (Citrullus lanatus Thunb.). S. Afr. J. Bot. 2020, 128, 333-338. [CrossRef]

35. Mo, R.; Yang, S.; Zhang, Q.; Xu, L.; Luo, Z. Vacuum infiltration enhances the Agrobacterium-mediated transient transformation for gene functional analysis in persimmon (Diospyros kaki Thunb.). Sci. Hortic. 2019, 251, 174-180. [CrossRef]

36. Chevreau, E.; Dousset, N.; Joffrion, C.; Richer, A.; Charrier, A.; Vergne, E. Agroinfiltration is a key factor to improve the efficiency of apple and pear transformation. Sci. Hortic. 2019, 251, 150-154. [CrossRef]

37. Gaba, V.; Kathiravan, K.; Amutha, S.; Singer, S.; Xiaodi, X.; Ananthakrishnan, G. The uses of ultrasound in plant tissue culture. In Plan Tissue Culture Engineering; Springer: Dordrecht, The Netherlands, 2006; pp. 417-426. ISBN 1402035942.

38. Faize, M.; Faize, L.; Burgos, L. Using quantitative real-time PCR to detect chimeras in transgenic tobacco and apricot and to monitor their dissociation. BMC Biotechnol. 2010, 10, 53. [CrossRef] [PubMed] 